University of Nebraska - Lincoln

DigitalCommons@University of Nebraska - Lincoln

2016

\title{
Distributed Cognition in Cancer Treatment Decision Making: An Application of the DECIDE Decision-Making Styles Typology
}

\author{
Janice L. Krieger \\ University of Florida, janicekrieger@ufl.edu \\ Jessica L. Krok-Schoen \\ Ohio State University Comprehensive Cancer Center, krok.5@osu.edu \\ Phokeng M. Dailey \\ Ohio State University - Main Campus, dailey.174@osu.edu \\ Angela L. Palmer-Wackerly \\ University of Nebraska-Lincoln, apalmer-wackerly2@unl.edu \\ Nancy Schoenberg \\ University of Kentucky, nesch@uky.edu
}

See next page for additional authors

Follow this and additional works at: https://digitalcommons.unl.edu/commstudiespapers

Part of the Bioethics and Medical Ethics Commons, Critical and Cultural Studies Commons, Gender, Race, Sexuality, and Ethnicity in Communication Commons, Medical Humanities Commons, Mental and Social Health Commons, and the Other Communication Commons

Krieger, Janice L.; Krok-Schoen, Jessica L.; Dailey, Phokeng M.; Palmer-Wackerly, Angela L.; Schoenberg, Nancy; Paskett, Electra D.; and Dignan, Mark, "Distributed Cognition in Cancer Treatment Decision Making: An Application of the DECIDE Decision-Making Styles Typology" (2016). Papers in Communication Studies. 71.

https://digitalcommons.unl.edu/commstudiespapers/71

This Article is brought to you for free and open access by the Communication Studies, Department of at DigitalCommons@University of Nebraska - Lincoln. It has been accepted for inclusion in Papers in Communication Studies by an authorized administrator of DigitalCommons@University of Nebraska - Lincoln. 


\section{Authors}

Janice L. Krieger, Jessica L. Krok-Schoen, Phokeng M. Dailey, Angela L. Palmer-Wackerly, Nancy Schoenberg, Electra D. Paskett, and Mark Dignan 


\title{
Distributed Cognition in Cancer Treatment Decision Making: An Application of the DECIDE Decision-Making Styles Typology
}

\author{
Janice L. Krieger,' Jessica L. Krok-Schoen, ${ }^{2}$ Phokeng M. Dailey, ${ }^{2}$ Angela L. Palmer-Wackerly, ${ }^{3}$ \\ Nancy Schoenberg, ${ }^{4}$ Electra D. Paskett, ${ }^{2}$ and Mark Dignan ${ }^{4}$ \\ I University of Florida, Gainesville, Florida, USA \\ 2 The Ohio State University, Columbus, Ohio, USA \\ 3 University of Nebraska-Lincoln, Lincoln, Nebraska, USA \\ 4 University of Kentucky, Lexington, Kentucky, USA \\ Corresponding author: Janice L. Krieger, College of Journalism and Communications, University of Florida, 2024 Weimer Hall, 1885 Stadium Road, \\ P.O. Box I I8400, Gainesville, FL 326I I, USA; email janicekrieger@ufl.edu
}

\begin{abstract}
Distributed cognition occurs when cognitive and affective schemas are shared between two or more people during interpersonal discussion. Although extant research focuses on distributed cognition in decision making between health care providers and patients, studies show that caregivers are also highly influential in the treatment decisions of patients. However, there are little empirical data describing how and when families exert influence. The current article addresses this gap by examining decisional support in the context of cancer randomized clinical trial (RCT) decision making. Data are drawn from in-depth interviews with rural, Appalachian cancer patients $(N=46)$. Analysis of transcript data yielded empirical support for four distinct models of health decision making. The implications of these findings for developing interventions to improve the quality of treatment decision making and overall well-being are discussed.
\end{abstract}

Keywords: cancer, treatment decision making, communication, health disparities, In-depth qualitative interviews, region, Appalachia, USA

Social networks have an influential role in determining an individual's health behaviors (Ackerson \& Viswanath, 2009; Lapinski \& Rimal, 2005). Although interpersonal influence occurs in a range of health contexts, the implications of illness severity on the types of messages that people exchange and how those messages affect treatment decision making are not well understood (O'Hair et al., 2003). Much of the treatment decision-making literature focuses on individual-level cognitive processes, such as rational and intuitive strategies for deciding how to act (Bogner \& Klein, 1997; Cader, Campbell, \& Watson, 2005; McNutt, 1989, 2004). More recently, there has been a shift to consider distributive cognition (or "shared mind") approaches in the realm of treatment decision making (Epstein, 2013; Epstein \& Gramling, 2013; Epstein \& Street, 2011). Distributed cognition refers to the idea that interpersonal discussion can result in cognitive and affective schemas being shared across two or more people. A patient who discusses treatment decisions with members of the social network may be exposed to new ideas that he or she could not arrive to on his or her own (Epstein, 2013). From this perspective, whether or not patients engage in conversations about their treatment choices and how patients perceive those interactions are central to understanding the decision-making process.

Distributive cognition in the context of health care decision making commonly focuses on interactions between patients and their physicians (Cegala \& Post, 2009; Epstein \& Street, 2011; Street \& Voigt, 1997). Although physicians are often an important source of health information for patients, they are not always the primary source of health-related social influence (Kapp, 1991). Indeed, previous research has shown 
that cancer patients frequently consult with spouses, adult children, and extended family members when making medical treatment decisions (Chouliara, Kearney, Stott, Molassiotis, \& Miller, 2004; Schumacher et al., 2008). The involvement of caregivers in treatment decision making is commonly considered a form of social support because these individuals assist patients in achieving their decisional goals by finding information relevant to treatments, expressing care, and even providing advice (Goldsmith \& Miller, 2014). However, it is unknown how much of the communication that occurs with caregivers on the topic of treatment decision making is focused on achieving the goals of a patient as compared with goals associated with attaining a particular decisional outcome.

There is significant evidence that patient decision making concerning participation in experimental forms of cancer treatment, such as randomized clinical trials (RCTs), is heavily influenced by the opinions of caregivers (Avis, Smith, Link, Hortobagyi, \& Rivera, 2006; Mills et al., 2006; Ross et al., 1999; Virani, Burke, Remick, \& Abraham, 2011). However, it is unclear why patient treatment decisions tend to mirror preferences of their caregivers so closely. To better understand this phenomena, it is necessary to distinguish between communication behaviors that help a patient cope with the emotional and informational burden associated with cancer (i.e., social support) and those that directly influence the outcome of a discreet treatment decision (decisional support). This distinction is theoretically useful because the latter is driven by strategic goals whereas the former is not. Messages produced with a strategic goal of achieving a particular treatment outcome are likely to incorporate social influence strategies such as guilt or framing (e.g., highlighting benefits, downplaying risks). Messages intended to be strictly supportive, however, are less likely to contain social influence appeals.

Following this logic, the current study seeks to explicate the nature of decisional support by examining the conditions under which cancer patients seek to involve their caregivers in treatment decisions as well as the extent to which caregivers influence the treatment option selected. Specifically, we explore whether patients desire greater autonomy or interdependence with caregivers in the cancer treatment decisionmaking process, as well as patients' perceptions of their caregivers' preferences. Finally, we demonstrate that the interplay of patient and caregiver preferences related to autonomy and interdependence can be used to illustrate four discreet treatment decision-making styles.

\section{Shared Mind: Distributed Cognition and Treatment Decision Making}

Communication is central to both the development of and the outcomes associated with distributed cognition (Roloff
\& Van Swol, 2007). Distributed cognition develops when the exchange of verbal and nonverbal messages over time results in cohesion. Cohesion refers to overlap in the cognitions and emotions of two or more individuals regarding a given situation. Establishing cohesion among caregivers is important in a variety of contexts, but it is particularly crucial in cases of serious illness. When families lack cohesion, patients can feel pressured to make decisions that are inconsistent with their values. For example, a patient may believe that continuing aggressive treatment is futile but do so anyway because his or her family perceives palliative care as giving up (Sedig, 2016). Thus, there must be some degree of cohesion between a patient and the family for effective decision making to occur (Epstein, 2013).

Conceptualizing communication as an outcome or product draws on the idea that the degree of cohesion among individuals will shape the type and extent of messages exchanged. According to Roloff and Van Swol (2007), shared mental models "improve and facilitate communication once they are formed" (p. 175). To illustrate, if a patient expresses a preference for a given treatment that his or her caregiver also views as being optimal, the treatment negotiation process would be expected to include little discussion of risks associated with treatment or alternatives to the treatment because both individuals have similar mental models of the situation. Conversely, if a patient wishes to pursue a particular treatment that his or her relational partner views as excessively risky, the lack of cohesion between the couple would be expected to yield more discussion about the benefits and risks of all available treatment options. The prediction that a high degree of distributed cognition simplifies the decisionmaking process and that a low degree of distributed cognition complicates the decision-making process makes intuitive sense. However, it is also true that the extent to which caregivers communicate about important health decisions is situated within broader relational norms (Goldsmith, Miller, \& Caughlin, 2008). This means that some families may engage in limited conversations about treatment decision making, even when there is a low degree of distributed cognition. Understanding how patients and their families negotiate autonomy within the context of relational norms is critical to understanding clinical outcomes in important treatment decisions, such as RCT participation.

\section{Patient Autonomy in Medical Decision Making}

Patient autonomy has long been a core concept in theories of physician-patient interaction (Charles, Gafni, \& Whelan, 1997; Entwistle, Carter, Cribb, \& McCaffery, 2010). Although maintaining autonomy is often conceived of as a patient's right, there is little consensus regarding what communication 
behaviors constitute exerting autonomy. Furthermore, most theoretical and empirical research has not examined the extent to which patients perceive responsibilities associated with this right. For example, some patients may feel burdened by being the sole decision maker and delegate that authority to someone else (Kapp, 1991). For the purposes of the current study, patient autonomy is defined as pursuing goals associated with the patient personally assuming all rights and responsibilities associated with decisional authority. This can occur as a result of a patient restricting opportunities for others to participate in medical decision making or as a result of others opting not to participate, leaving the patient as sole decision maker by default. Because not all patients desire or are able to exert autonomy in the decision-making process, we now turn to a brief overview of patient interdependence in health decision making.

\section{Patient Interdependence}

If individuals other than the patient have an active role in health decision making, then the patient has some level of interdependence (Pecchioni \& Nussbaum, 2000). Patient interdependence refers to pursuing goals associated with distributing at least some of the rights and responsibilities associated with decisional authority to individuals other than the patient. A preference for interdependence in decision making can include individuals with medical expertise (e.g., health care providers) and/or trusted caregivers (e.g., family members). Although the process of shared decision making between patients and health care providers is well documented in the literature, there are relatively few studies examining why patients share the rights and responsibilities of decision making with caregivers (Kapp, 1991). One potential reason is that interdependence can minimize patient burden by reducing feelings of personal responsibility for a given outcome. It may also alleviate the potential for conflict that would result if caregivers disagreed with a patient's decision. Finally, some patients feel it is unethical not to include caregivers in decision making when they will likely bear burdens (i.e., emotional, financial, or physical) as a result of the medical decision that is made.

Caregivers who pursue interdependence can be characterized as providing the patient with decisional support. Although few studies have explicitly examined decisional support (see Arora, Finney Rutten, Gustafson, Moser, \& Hawkins, 2007, for an exception), the involvement of the social network in decision making is typically considered a form of social support (Goldsmith, 2004). There are similarities between decisional support and social support in that both types of assistance can be provided with or without being desired by the patient. However, decisional support differs from social support in important ways, meaning patients in the midst of important treatment decisions can receive both decisional support and social support, either decisional or social support, or neither. Below, the distinctions between decisional and social support are described in greater detail.

\section{Distinction Between Decisional Support and Social Support}

Caregivers who help patients make health care decisions are commonly described in the literature as providing social support. Social support refers to engaging in communication behaviors intended (by the provider of the support) to assist a patient (Heaney \& Israel, 2008). Social support is typically divided into subtypes, which include emotional (i.e., love, caring, sympathy), instrumental (i.e., help, assistance with tangible needs), informational (i.e., advice or information), and appraisal (i.e., feedback, decision making) support (House \& Kahn, 1985). Studies have shown that social support can enhance the psychological and social well-being of an individual (Janssen \& Pfaff, 2005). There are also numerous negative outcomes (e.g., poor coping, distress) associated with social support (Manne \& Glassman, 2000; Uchino, 2009).

A likely reason for these contradictory findings is the lack of conceptual specificity about the types of social support being provided and the goals of specific interactions (Krieger, 2014a). The clearest example is advice giving. Giving advice about medical decision making is one of the primary ways caregivers provide social support to patients. This categorization assumes that advice is given with the relational goal of assisting the patient (i.e., patient-focused communication). Although this is certainly true in some cases, treatment decisionmaking research has ignored other potentially salient goals that may motivate giving advice. One such motivation is the desire to influence a patient to pursue a particular course of action, such as seeing a particular physician, seeking a second opinion, or choosing a particular treatment. These behaviors are outside the scope of what is considered social support because the communication is motivated by instrumental, rather than relational, goals. When communication about medical decision making is motivated by instrumental goals, caregivers seek to share some of the rights and responsibilities associated with decisional authority.

Following this logic, there is a need to understand the role of caregivers in medical decision making outside the realm of social support. Our focus is on decisional support, which is defined as communicative behaviors that reallocate some of the rights and responsibilities associated with decisional authority in treatment decision making. Patients are likely to vary on the level of decisional support they desire as a function 
of individual differences. Similarly, patients are likely to vary on the level of decisional support they receive based on family communication norms as well as the resources available for assuming responsibility for a decision (e.g., medical expertise). Next, we explore how decisional support relates to patient outcomes.

\section{Decisional Support and Patient Outcomes}

There are a number of discreet communication behaviors that caregivers may use to provide decisional support to a patient, including seeking information, asking questions, and providing opinions (Charles et al., 1997). There are mixed findings regarding the benefits and challenges posed by involving caregivers in decision making. Some studies report uniformly positive outcomes, whereas others suggest the involvement of family can create significant conflict both during the decision-making process and once the decision has been made (Hauke, Reiter- Theil, Hoster, Hiddemann, \& Winkler, 2011; Hilton, 1994; Speice et al., 2000; Zhang \& Siminoff, 2003). For example, caregivers who interact directly with a health care provider can make patients feel left out of the decision- making process (Speice et al., 2000).

Conflict can also occur when the family disagrees with a patient's medical treatment decision. Relatives disagree with patients about what treatments to pursue about a third of the time (Hauke et al., 2011; Zhang \& Siminoff, 2003). Zhang and Siminoff (2003) found that decisional conflict occurs in response to choices about routine treatment, discontinuation of curative treatment, and hospice care. Others have found that disagreements tend to be in the direction of relatives preferring more aggressive treatment than the patient and physician (Hauke et al., 2011). The potential for family conflict over treatment decisions is heightened when one (or more) of the choices is associated with a high degree of uncertainty (Krieger, Palmer-Wackerly, Dailey, et al., 2015). For these reasons, we now review the role of caregivers on health decisionmaking outcomes in a context associated with a high degree of uncertainty: the opportunity to participate in experimental cancer research.

\section{Treatment Decision Making and Cancer Clinical Trials}

RCTs are considered the most effective tool available for treatment evaluation (Brown, Butow, Ellis, Boyle, \& Tattersall, 2004; Loh, Butow, Brown, \& Boyle, 2002). For cancer patients, the decision to participate in an RCT is often complex, and one where individuals are frequently required to make a decision soon after diagnosis (Avis et al., 2006). The goal of a cancer RCT is to confirm the effectiveness of a promising new treatment by comparing it with the current standard of care (Freedman, 1987). There are both benefits and risks associated with RCT participation. Benefits include gaining access to new treatments that are not yet publicly available, or the satisfaction of contributing to advancements in medical research. Risks include unknown side effects from experimental treatment or medications or reduced treatment efficacy as compared with standard treatment.

One unique characteristic of RCT decision making, as compared with other types of treatment decision making, is that patients must consent to participate without knowing which treatment they will receive. The use of randomization can lead to confusion among patients regarding how their treatment will be chosen as well as concerns that the randomization process itself poses risk (Krieger, 2014b; Krieger, Palmer-Wackerly, Dailey, et al., 2015; Krieger, Parrott, \& Nussbaum, 2011). Furthermore, patients may refuse to enroll in an RCT due to the uncertainty associated with experimentation (Brown et al., 2004). These concerns are likely to be more salient among patients who are members of vulnerable populations, such as rural Appalachians and ethnic minorities (Baquet, Commiskey, Daniel Mullins, \& Mishra, 2006). The focus of the current article is people living in rural areas of Appalachia, a cultural region in the United States extending from New York in the north to Mississippi, Alabama, and Georgia in the south. Appalachia is designated as a medically underserved area due to the high burden of disease among its inhabitants relative to the general population (Baquet et al., 2006). Two important health inequities affecting this region are the significantly higher rate of cancer mortality and lower rates of participation in cancer RCTs that provide access to state-of-science treatment (Friedrich, 2002; Huang, Wyatt, Tucker, Bottorff, \& Lengerich, 2002).

One novel strategy for understanding the disconnect between higher rates of cancer mortality coupled with the low rates of RCT participation in the Appalachian region is to more clearly understand the role of caregivers in patient RCT participation. Although caregivers are likely to be involved in some way throughout the cancer treatment decision-making process, the high levels of both mortality salience and uncertainty that characterize RCT decision making may result in individual patients desiring higher or lower levels of autonomy. Similarly, these same factors may result in patients perceiving that their caregivers desire more or less involvement (i.e., interdependence) in a patient's RCT decision. Thus, we pose the following research questions:

Research Question 1 (RQ1): How do rural, Appalachian cancer patients express preferences for decisional support from their caregivers when considering a cancer RCT? 


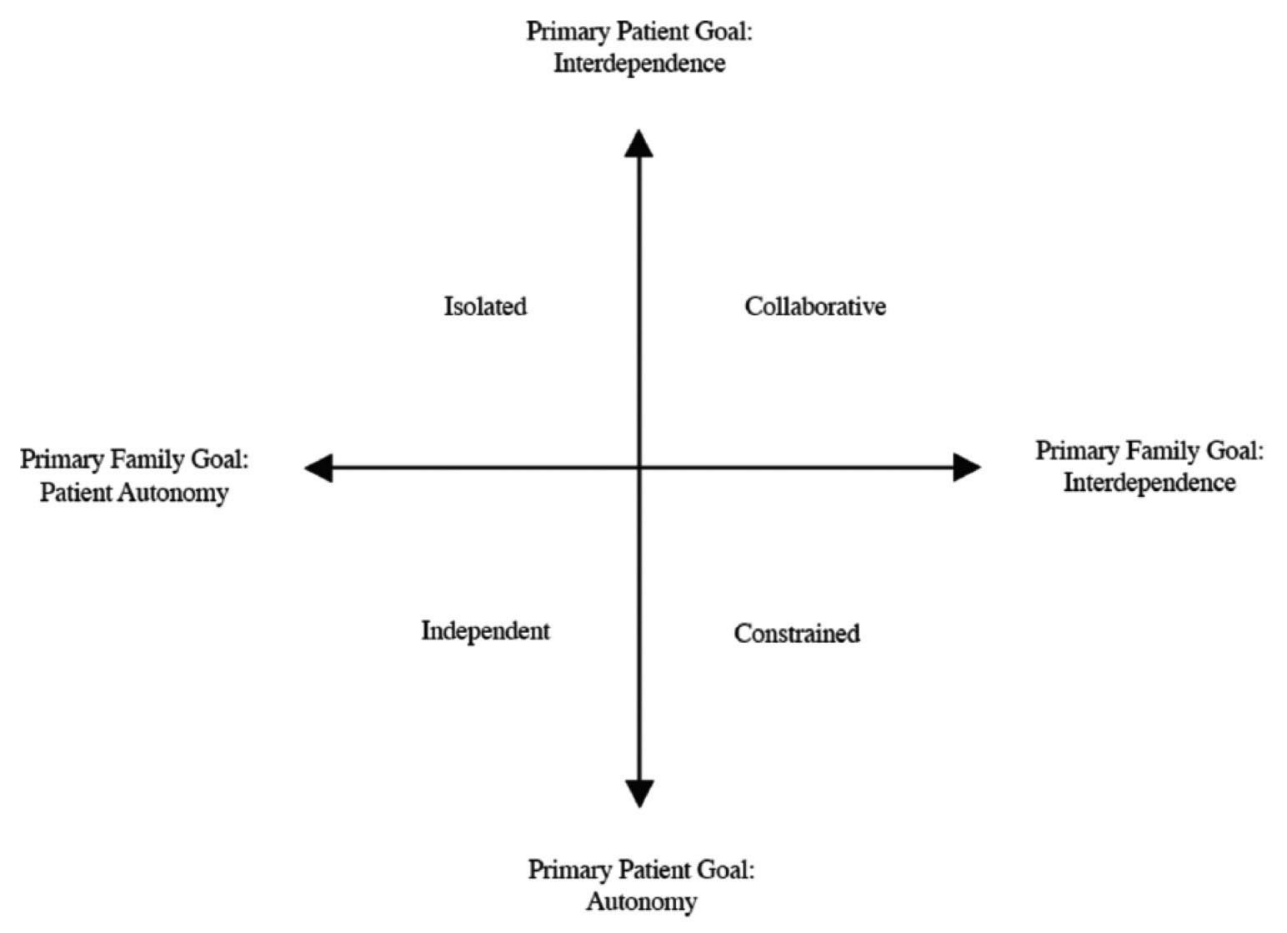

Figure I. Typology of family decision-making styles.

Research Question 2 (RQ2): How do rural, Appalachian cancer patients perceive family preferences related to providing decisional support when considering a cancer RCT?

\section{Decisional Support and Family Decision-Making Styles}

Two key questions likely to influence the course of decision making are how much decisional support a patient desires following a treatment disclosure as well as the perceived degree to which the patient receives decisional support. The Family DECIDE (Determinants of Clinical Decision Making) Typology considers the extent to which patients desire decisional support ( $y$ axis) and the extent to which they perceive receiving decisional support ( $x$ axis) to propose four distinct styles of family decision making (see Figure 1; Krieger, 2014a). This configuration, moving clockwise from the bottom left, yields the following decision-making styles: independent, isolated, collaborative, and constrained. However, it is unknown what family decision-making styles patients considering a cancer $\mathrm{RCT}$ will utilize. We pose the following question:

Research Question 3 (RQ3): What type of family health decision-making style do rural, Appalachian cancer patients rely on when offered the opportunity to participate in a cancer RCT?

\section{Method}

Participants

Participants were 46 cancer patients who were offered a cancer treatment RCT. To be included in the study, participants had to live in or seek treatment in one of the 32 rural Appalachian counties in Ohio. Patients were identified by health care staff who worked at a large, urban cancer center and three rural, community cancer clinics located in the Appalachian region. Participant ages ranged from 33 to 80 years $(M=59.9$ years, $S D=11.6$ years). Most participants were female $(60.9 \%)$, White (95.7\%), and married (87\%). Approximately, $70 \%$ of participants had a high school diploma or some college education and $54 \%$ of participants identified their work as skilled labor. The three most common types of cancer among patients were breast (41.3\%), multiple myeloma (19.6\%), and prostate (15.2\%) and most participants had health insurance through their job (47.8\%) or Medicare (30.4\%).

\section{Procedures}

Recruitment. The research team conducted recruitment in two ways, depending upon the preference of the cancer clinic. For patients at three of the clinics, the RCT nurse sent the names of patients who had been offered an RCT to the research staff. A member of the research team prepared letters from the 
Table I. Treatment DM Constructs, Description, and Examples.

\begin{tabular}{|c|c|c|}
\hline Constructs & Description & Examples \\
\hline I. Patient preference for autonomy in DM & $\begin{array}{l}\text { Statements expressing patient preference of } \\
\text { accepting rights and responsibilities of DM }\end{array}$ & $\begin{array}{l}\text { "It's my body, it's my life, you know l'm going } \\
\text { to do what I want." }\end{array}$ \\
\hline $\begin{array}{l}\text { 2. Patient preferences for interdependence } \\
\text { with family caregivers in DM }\end{array}$ & $\begin{array}{l}\text { Statements expressing patient preference } \\
\text { for sharing rights and responsibilities of DM } \\
\text { with family caregivers }\end{array}$ & $\begin{array}{l}\text { "She's my wife. You know I share everything } \\
\text { with her, you know, we talk pretty much ev- } \\
\text { erything over. I don't do much without dis- } \\
\text { cussing it with her." }\end{array}$ \\
\hline $\begin{array}{l}\text { 3. Patient perceptions that family caregivers } \\
\text { preferred them to be autonomous in their } \\
\text { treatment DM }\end{array}$ & $\begin{array}{l}\text { Statements expressing patient's perception } \\
\text { that the family caregiver refuses to give ad- } \\
\text { vice, ignore discussions of treatment, does } \\
\text { not offer support, and so forth. }\end{array}$ & $\begin{array}{l}\text { "He didn't know whether I should or } \\
\text { shouldn't [referring to clinical trial] or, you } \\
\text { know, but ultimately l'd have to be the one } \\
\text { that made the decision." }\end{array}$ \\
\hline $\begin{array}{l}\text { 4. Patient perceptions that family caregiv- } \\
\text { ers preferred them to be interdependent in } \\
\text { their treatment DM }\end{array}$ & $\begin{array}{l}\text { Statements expressing patient's perception } \\
\text { that the family caregiver initiates discussion } \\
\text { of treatment, encourages selection of one } \\
\text { option over another, asks for updates, and } \\
\text { so forth. }\end{array}$ & $\begin{array}{l}\text { "If I kept them out of the loop [referring to } \\
\text { treatment options], they'd be all over me." } \\
\text { Note. DM = decision making. }\end{array}$ \\
\hline
\end{tabular}

cancer physicians and emailed them to the RCT nurse, who procured the physicians' signatures and returned them in hard copy form to the research team. The research team then printed envelopes and mailed the recruitment letters to patients. To schedule interviews with interested patients, multiple follow-up phone calls were made, starting 2 weeks after patients received the letter. For patients at the fourth clinic ( $n=$ 3 ), the health care staff preferred to contact patients with letters sent from their facility, asking patients to contact the research team whether they were interested in participating in our study. No follow-up phone calls were made.

Interviews. Once the study was approved by the Ohio State University Institutional Review Board, a member of the research team was trained in interviewing techniques and consulted with two members of the Appalachian community to revise interview questions for clarity and cultural sensitivity. In-depth, semi-structured interviews were conducted over 11 months (Patton, 2002). Interviews were audio-recorded, ranged in length from 30 minutes to 3 hours, and occurred in a location of the participant's choice (e.g., participant's home, restaurant, coffee shop, hospital cafeteria). Whenever possible, interviews were conducted in a private location; however, for six interviews, other members of the family were present. Once the interviews were completed, the researcher asked participants to complete a demographic survey. Patients received a US $\$ 30.00$ gift card to thank them for their participation.

\section{Interview Analysis}

Audio files were uploaded to a password-protected computer and transcribed verbatim. Analysis proceeded in several phases. In the first phase, four researchers read through 10 interview transcripts to (a) become familiar with the overall content and (b) identify the units of analysis that illustrated the patient's decision-making preference (i.e., autonomous vs. interdependent) and the patient's perception of the caregiver's decision-making preference (i.e., autonomous vs. interdependent). Each researcher unitized transcript data into thought units. Thought units were defined as discreet utterances concerning one aspect of RCT decision making. Thought units ranged in length from a short clause to several sentences. Another member of the research team reviewed each transcript to establish inter-rater agreement on unitization. Disagreements about the number or composition of thought units were resolved through discussion.

In the second phase of analysis, a trained team of six undergraduate research assistants coded each thought unit using a theoretically derived codebook consisting of a conceptual definition and example for each construct. The constructs of interest in the current investigation are (a) patient decision-making preferences associated with autonomy, (b) patient decisionmaking preferences associated with interdependence, (c) patient perceptions that a family caregiver desired them to be autonomous in their treatment decision making, and (d) patient perceptions that a family caregiver desired them to be interdependent (see Table 1). Research assistants received 20 hours of training in qualitative data analysis, NVivo software, and the codebook. They practiced coding using sample transcripts until an acceptable agreement (>90\%) was reached. The research assistants then read through each transcript twice, created a conceptual memo for every transcript, and coded thought units. Krippendorff's alpha was calculated for each of the four codes to establish inter-rater reliability. 


\section{Results}

\section{Preliminary Data Analysis}

Of the 46 participants health care providers referred to the study because they were offered an RCT, 35 (76.1\%) patients enrolled in an RCT. Among the 11 participants who did not participate, eight reported explicitly declining whereas three did not remember the RCT being offered as a treatment option. One patient reported declining the RCT when it was offered but was recorded as consented by the health care provider. Preliminary analysis of the transcripts yielded 684 thought units related to RCT decision making. The number of thought units in each transcript ranged from zero $(n=3)$ to $37(M=14.72$, $S D=7.92)$. Among these, thought units related to personal preferences for decision making ranged from zero to $27(M=$ $10.48, S D=6.55$ ) and thought units related to perceived family preferences for decision making ranged from zero to 11 ( $M$ $=4.24, S D=2.56$ ).

\section{Patient Preferences for Autonomy or Interdependence (RQI)}

Autonomy. There were 345 utterances about patient preferences coded as reflecting a preference for autonomy in RCT decision making ( $M=7.50, S D=4.77$, Krippendorff's $\nabla=.96)$. Statements expressing a preference for autonomy were those in which the RCT decision making was framed as the patients' rights and/or responsibility. A preference for autonomy was often reflected as my body, my choice approach to treatment decision making. Bonnie, a 33-year-old breast cancer patient who enrolled in an RCT, put it this way: "When it comes right down to it, like it's my-it's my body, it's my life—I'm going do what I want."

In some cases, a preference for autonomy resulted in a rapid decision to pursue participation in the RCT. These immediate decisions tended to correspond with altruistic motives. For example, Bonnie said she enrolled in the RCT because "I don't ever think about myself, so it didn't even cross my mind that it would-you know could possibly benefit me. I was thinking about benefiting others." Similarly, Veronica, 56 , another breast cancer patient who enrolled in an RCT, stated, "I finally decided that somebody had to do these clinical studies to get to where it is right now for them to be able to do what they did for me." Some patients saw participating in an RCT as a way to contribute to the scientific community. For example, Jane, a 57-year-old lung cancer patient, said she enrolled in her RCT because "I don't have any kids. I've never contributed anything to the world and I thought I could contribute this to science."
In other cases, aversion to some aspect of the RCT resulted in an autonomous (and often immediate) decision not to participate. The two most common factors were the perception that the RCT involved receiving extra or potentially unnecessary treatments and, relatedly, the amount of time the RCT would require that the patient spend in the hospital as a result of longer appointments, more frequent appointments, or extending the duration (e.g., weeks or months) of treatment. For instance, Denise, 73, said she did not enroll in an RCT because "I really don't want to take anything more than what I have to." Cathy, 65 , was considering participating in a lung cancer RCT, but later changed her mind and declined enrollment: "I got the papers ... When they said a year, I thought, 'That's it. I'm not doing this." Similarly, Madeline, 65, described how she reacted when she was offered participation in an RCT the first time she was diagnosed with breast cancer: "All I could think of was how fortunate I was that it was gone and I shouldn't take up any more of his time."

Interdependence. There were 137 utterances about patient preferences coded as reflecting a desire for interdependence in RCT decision making $(M=2.98, S D=3.94$, Krippendorff's $\otimes=.79)$. When patients expressed preferences for interdependence, most utterances related to discussing treatment options with a family member and stemmed from established norms for communication within their families. Married patients frequently mentioned their spouse as a source of decisional support. Eddie, 58-year-old prostate cancer patient, described relying on his spouse to help compensate for his confused emotional state while he was making his decision. He said, "Your mind's going a hundred miles an hour and your emotions are going so you need to discuss it." Eddie, who enrolled in an RCT, described his conversations about treatment with his wife as an extension of their marital norms for communication, "We pretty much have an open dialogue about most things. So it was a normal thing for me to do. For us to do." Carmen, a 36-yearold breast cancer patient who enrolled in an RCT, also felt that the process for making her RCT decision reflected broader relational norms. She said, "... Being that he is my husband, I do value his opinion and what he thinks ... I think that, yes, it is my body and everything, but I married him because I trusted him."

Some patients also sought interdependence from caregivers other than their spouse. Adult children were commonly mentioned as a source of decisional support. For Larry, a 74-yearold prostate cancer patient, the relational closeness he felt with his adult children merited keeping them updated on his decision-making process. He stated, 
They [the children] were all allowed to express their concerns ... They can argue with us. Not argue, but say, "Well, what about this and what about this and have you considered this." Our family is very close.

He specifically relied on his son for decisional support when he decided to enroll in an RCT because he was a physician: "He just had more to offer in the way of knowledge and information." Female patients frequently mentioned sisters as a source of decisional support. Madeline, a 65-year-old breast cancer patient who enrolled in an RCT, relied heavily on her sister for decisional support during her second cancer diagnosis because her husband had dementia and she felt that talking about it "would scare him."

\section{Patient Perceptions of Caregiver Preferences for Autonomy or Interdependence (RQ2)}

Patient autonomy. There were 101 utterances related to patient perceptions that caregivers desired them to be autonomous in their RCT decision making $(M=2.20, S D=2.16$, Krippendorff's $\nabla=.79)$. The primary way this preference was communicated to patients was not providing an opinion about whether participating in the RCT was good or bad. For instance, Jane, a 57-year-old lung cancer patient who enrolled in an RCT, said, "You know what? They all let me decide." Gloria, 50, commented about her decision to enroll in a lung cancer RCT, "Once I read everything over and thought about it, my husband wouldn't say yes or no. Nothing. It was like talking to a stump." Other patients added that their loved ones did not have enough information to have an opinion. Alice, 74, decided to enroll in a breast cancer RCT. She said that her daughter would not give her opinion but "Went along with what I decided because she wasn't there to hear the doctor." Similarly, Gwen, 52, said she was unsure about whether to participate in an ovarian cancer RCT, so she asked her spouse for his opinion. She says, "He didn't know whether I should or shouldn't, you know, but ultimately I'd have to be the one that made the decision." She ultimately declined the RCT.

Interdependence. There were 101 utterances related to patient perceptions that caregivers desired them to be interdependent in their RCT decision making $(M=2.04, S D=2.35$, Krippendorff's $\otimes=.70$ ). Patient perceptions about interdependence centered on caregivers providing decisional input by explicitly telling them what they believed was the optimal treatment decision. For instance, when Joanie, 76, told her daughter that she was considering participating in an RCT, her daughter responded with, "Do it, mom." Joanie, who had lung cancer and enrolled in an RCT, said, "She wanted me to be cured. I told her, 'I was told they can't cure it, but they can control it.' But she said, 'I want you cured." In this example, Joanie's daughter insisted that her mother participate in the RCT because she had unrealistic expectations about the efficacy of the treatments being tested. Rose, a 70-year-old breast cancer patient, described her husband's involvement in her RCT decision in a similar way, "He told me I had to-it wasn't good that I had to do it-but he knew that it had to be done." In this case, Rose's husband perceived participating in the RCT to be the only reasonable course of action and insisted that she do it to have the best chance of getting well. Other patients were recipients of direct advice or opinions due to their experience with or knowledge about RCTs. When Eddie, 58, was considering participating in an RCT for his prostate cancer, he called a relative of his neighbor who had metastatic prostate cancer. The advice he received was, “'Don't even hesitate about getting in this program. You call them tomorrow. And you get into it.' He said, 'if this was available when I was having my treatment I would have done it knowing what I know now."' Eddie enrolled in the $\mathrm{RCT}$.

\section{Identifying General Styles of Health Decision Making (RQ3)}

Finally, we sought to determine how utterances reflecting a patient's preferred decision-making style and their perceptions of caregiver preferences for decision making could be examined jointly to classify patients into one of the main treatment decision-making styles seen in Figure 1. Values for the patient preferences dimension were determined by subtracting the number of utterances expressing a desire for autonomy in decision making from the number of utterances expressing a desire for interdependence in decision making. Values for the patient perceived caregiver preference dimension were created by subtracting the number of utterances expressing perceived caregiver preferences for patient autonomy from the number of utterances expressing a perceived caregiver preference for patient interdependence. Both variables were then dichotomized using a mean split. We compared patient preferences and perceived caregiver preferences to identify the predominant RCT decision-making style used by each patient. The results of this procedure resulted in nine patients using an independent style, 11 using a collaborative style, 15 using an isolated style, and 11 using a constrained style. Below, characteristics of each decision-making style are described in more detail.

Independent. Patients with an independent decision-making style $(n=9)$ had a high level of desired autonomy and perceived that caregivers supported their autonomy in the health care decision-making process. In some cases, this was a result of not disclosing to caregivers that a decision-making opportunity 
existed. This included situations mentioned previously when patients exercised autonomy by making the decision about whether to participate in the RCT very quickly. In other cases, patients disclosed the opportunity to make a decision to caregivers out of obligation, but did not expect or desire their involvement in the decision-making process. Cathy, a 65-year-old lung cancer patient who did not enroll in an RCT, exemplifies this perspective. She described her decision-making process in this way:

And, you know, they need to have an opinion, although I think it's left up to the individual as to who makes that decision. You know, I felt this is my body, I'm going do what I want do, right or wrong. . . It's still my body and it's my decision. It's not yours. It's not my daughters'. It's not my mother's. It's mine.

Isolated. The second decision-making style, isolated, describes patients who desired decisional support from one or more caregivers, but their needs for support were not met $(n=15)$. For example, one breast cancer patient, Tracy experienced significant frustration because she wanted her husband to give his opinion on whether or not she should participate in the RCT, but he would not. Tracy, 53, said,

I tried to talk to my husband about it, but I don't think he really even heard me. He's got a lot going on everywhere and he was just so bombarded with ... We've just got a lot going on in our life.

Ultimately, Tracy decided not to enroll in the RCT. However, she would have felt more confident in her decision if she had received some level of decisional support from her spouse.

Constrained. The constrained decision-making style refers to situations in which patients had a low desire for decisional support, but reported a strong caregiver preference for providing decisional support $(n=11)$. This type of situation was typical when a patient informed his or her caregiver of the decisional opportunity out of duty and the caregiver viewed the disclosure as an opportunity to influence patient decision making. One example is Angel, 59, a patient who disclosed to her daughter that she found a breast lump. The daughter insisted that her mother seek follow-up treatment, which she resisted. Angel's daughter then invited her to go with her to her yearly check-up and, without her mother's knowledge or consent, asked the physician to examine her mother's breast lump. As a result of the examination, Angel was diagnosed with Stage II breast cancer. After her lumpectomy at the local hospital, her family was skeptical of the surgeon's recommendation that she not receive any follow-up care. Angel described, "And my brothers and sisters and my daughter, everybody, my husband, said you need to get to Columbus and get a second opinion. I sort of dragged my feet, you know, I didn't want to do it."

In this situation, the patient did not want to pursue diagnostic options for her lump and also did not want to obtain a second opinion on her course of treatment. In both cases, feeling obliged to go along with her family's wishes may have saved her life. Nonetheless, it captures the manner in which friends and family coerce patients to achieve a degree of control over the process. Although tricking someone into being diagnosed is extreme, there are subtler ways individuals may make patients feel obligated to incorporate them in the decision-making process. Cathy, who was interviewed because of her own lung cancer diagnosis, described how she decided to accompany her parents to appointments to gain greater control over the decision-making process when her father had cancer: "I got so aggravated at [my mother] when my dad had cancer. They only heard what they wanted to hear the positive or the negative, and they'd just dwell on that. So I started going with them." These narratives illustrate patient experiences in the constrained decision-making style in which patient and caregiver treatment preferences were at odds.

Collaborative. The collaborative decision-making style refers to situations in which the patient had a high desire for decisional support from the caregiver and the patient perceived that the caregiver was willing to provide decisional support. Tim, 70, was diagnosed with Stage III prostate cancer and enrolled in an RCT. After his diagnosis, he brought his wife, three daughters, two grandchildren, and his pastor to his first appointment with his radiation oncologist. At this appointment, the oncologist offered him the opportunity to participate in an RCT comparing the standard of care (i.e., radiation to the prostate) with radiation of the entire pelvic region. When asked how he made his decision to enter the RCT, he said,

I talked to the family. I mean, we get around the table, setting in the living room or wherever, all three of the girls, the grandkids, and we said, "Hey, what do you guys think?" Instead of me saying yes or no. And we've never made decisions, even my kids don't make a decision on their own. A major decision, everybody gets together.

Patients may negotiate different degrees of collaboration in treatment decision. Whereas Tim approached the decisionmaking situation as one in which each person had an equal say, other patients negotiate collaboration to various degrees. For example, Denise, a 73-year-old breast cancer patient, invited her family to participate in her RCT decision-making process by helping her find information. The particular RCT she had 
been offered was testing the efficacy of adding an additional medication to what a person with breast cancer would normally receive with conventional treatment. Denise felt strongly that a person should not take any more medications than was absolutely necessary because of the possibility of side effects. Although she believed that not participating in the RCT was most consistent with her values, she invited her husband, son, and daughter to search the Internet and search for information to see whether the family agreed with her decision. She recounted a comment by her son that helped her feel confident in her decision to decline participation. He said, "Mom, you don't have to. Do what you want do, but you don't have to."

Another example is Ella, 66, who was taken to the emergency room due to extreme abdominal pain and diagnosed with colon cancer upon her arrival. After surgery to remove the most cancerous portions of the colon, she had to decide whether to pursue further surgery, chemotherapy, radiation, or participate in an RCT. Ella's husband, Rich, accompanied her to the emergency room, all her clinical appointments, and was present during her initial surgery. Ella, who ultimately did not participate in the RCT, described the decision-making process this way:

I leave it up to him. He's good at taking care of me so I justnow if he'd said surgery I probably would have said surgery. But he says, "It's up to you, let's try radiation first." And I said, "okay, that will be fine."

\section{Discussion}

Treatment decision making is one of the most common cancer-related topics patients discuss with caregivers (Goldsmith \& Miller, 2014). The frequency of treatment decision-related conversations reflects the reality that opportunities to make important decisions, such as whether to participate in cancer research, can be stressful for patients. In some cases, this stress is derived from the cognitive burden of decision making, such as processing a high volume of complex treatment information in a short amount of time (Cader et al., 2005; McNutt, 2004). In other cases, patients experience difficulty negotiating the relational element of the decision-making process, such as achieving a balance between autonomy and interdependence with their health care provider (Epstein, 2013; Epstein \& Street, 2011). Although cognitive, intuitive, and patient-provider perspectives of health decision making are valuable, there is still a gap in understanding decision making within the broader social contexts in which patients must make treatment choices.

Currently, there are few theoretical explanations for how patients reconcile conflicting points of view about their health care choices, regardless of whether the conflict is between a health care provider and caregivers or among caregivers. The current article advances understanding of the importance of the broader social context by examining distributed cognition among patients and caregivers regarding autonomy and interdependence. Patients who had caregivers who were not of shared mind about how the treatment decision would be made commonly expressed frustration with the types of supportive behaviors caregivers enacted as well as negative feelings about the treatment decision itself. These findings build upon and extend research on the unique relational challenges associated with treatment decision making (Goldsmith \& Miller, 2014; Goldsmith, Miller, \& Caughlin, 2008; Krieger, PalmerWackerly, Krok- Schoen, et al., 2015).

\section{Decisional Support in Cancer RCT Decision Making}

Decisional support occurs when caregivers assume some of the rights and responsibilities associated with medical decision making. In some cases, patients in the current study reported that the provision of decisional support helped reduce the perceived burden of decision making. Specifically, having conversations about treatment options with caregivers helped patients perceptually redistribute the responsibility for the treatment decision from themselves to all parties involved. Common ways these conversations occurred were as a result of caregivers attending appointments where treatment options were discussed, finding alternative sources of information about the treatment options offered, and giving advice.

Importantly, not all patients desired decisional support. In such cases, patients focused more on the rights associated with decision making, rather than the responsibilities. Patients who desired high levels of autonomy associated receiving no decisional support (or very low levels) with the ability to make a treatment choice that best suited their medical situation without managing emotions, information, and advice from others. Patients negotiated autonomy in treatment decision making in various ways. One method was concealing their diagnosis from loved ones (e.g., spouse, adult children) until treatment was decided. Another common strategy was informing caregivers of the diagnosis paired with indirect and direct strategies for maintaining autonomy. Indirect strategies included avoiding discussions about treatment altogether or explicitly stating who would be making the treatment decision (e.g., patient in conjunction with physician). Unfortunately, there are few scientific studies (if any) that illuminate how personal characteristics and relational qualities intersect to promote high levels of patient autonomy in treatment decision making. This is a fruitful direction for future research to explore. 
Some patients who desired autonomy were unable to achieve it due to a misalignment between a caregiver's supportive behaviors and the patient's goals for treatment or their relationship with their caregiver (Caughlin, 2010). For example, patients in the constrained decision-making style desired to make their RCT decision autonomously, but reported caregivers engaged in unwanted decisional support behaviors, including tricking them, accompanying them to appointments uninvited, or expressing unsolicited opinions. It cannot be determined from the current data whether patients' strategies for negotiating autonomy with caregivers were simply ineffective or whether caregivers ignored patient efforts to exert autonomy. What is clear from the current data is that receiving unwanted decisional support negatively influenced patient perceptions of the decision-making process as well as the patient's sense of well-being. This was particularly salient in cases when unwanted decisional support was provided in the form of advice. Research on unsolicited advice has shown that participants are likely to view advice negatively when it is perceived as controlling, critical, and/or conflicting with recipients' desire for acceptance and autonomy (Goldsmith \& Albrecht, 2011). Next, we consider the implication of advice in the treatment decision-making context in light of the social support literature.

\section{Reconceptualizing Advice as Decisional Support}

Of the many behaviors that could constitute decisional support, advice emerged as having a higher degree of relational complexity than others. Advice is often considered a form of information support (Goldsmith, 2004). The current data partially support this view, in that patients desiring high interdependence generally perceived advice giving from caregivers as being desirable. Patients in the collaborative decision-making style reported appreciation of the advice they received whereas those in the isolated style expressed being disappointed by the lack of advice they were given. Patients desiring high levels of autonomy had a different perspective. In such situations, patients interpreted treatment advice from caregivers as direct or indirect attempts at social influence. This pattern is a defining feature of the constrained decision-making style. Patients wanted to maintain the rights associated with medical decision making, but felt caregivers undermined those rights by emphasizing the responsibilities associated with decision making or demanding to have some control over the decision.

\section{Practical Implications}

Advancing understanding of the importance of communication in the negotiation of patient treatment preferences has important practical implications. The first is distinguishing between social support more generally and decisional support, in particular. Although nearly all patients may benefit from some form of social support from caregivers, not all desire decisional support. This stands in contradiction to current guidance given to patients and caregivers, such as the Family Caregivers in Cancer (Physician Data Query [PDQ৫]) on cancer.gov, which states, "Doctors, caregivers, and patients are partners in making decisions." Instead, patients and their caregivers may want to be instructed to discuss their decision-making preferences and be given the tools to have productive conversations. Establishing a norm that caregiver members should be equal partners in decision making may be as harmful to patients with a preference for autonomy as it is to eliminate caregivers from the decision-making process for patients with a preference for interdependence.

It is important for patients and caregivers to negotiate the type and amount of decisional assistance the patient desires, especially the extent to which patients want caregivers to ask questions of a health care provider or provide advice. When a patient desires a high degree of autonomy in decision making, too many questions on the part of the caregiver can be perceived as attempting to direct the decision- making process. Similarly, caregivers who provide specific advice about whether or not to make a specific decision can be perceived as attempting to control the patient, rather than assisting them. On the other hand, some patients want and need these types of decisional support.

\section{Strengths and Limitations}

The current article benefits from a number of strengths. Examining the role of caregivers in medical decision making is a novel approach for understanding RCT decisions. This is particularly important because previous shared health decisionmaking research has largely focused on communication and decision-making preferences within the physician-patient context (Cegala \& Post, 2009). Methodological strengths include recruitment from an underrepresented population and a mixed methods approach to data analysis. Coding utterances provide an unobtrusive way to evaluate patient perspectives on autonomy and interdependence in their cancer treatment decision making.

As with all research, there are limitations of the current article that should be noted. First, we only considered patientlevel data. It is possible that caregiver data may yield discrepant results such that caregivers may report a decision-making style preference that is incongruent with a patients' perception of the caregivers' desire to be involved in the RCT decision. Second, we only examined autonomy and interdependence in 
the context of caregivers. Health care provider treatment recommendations may influence the level of uncertainty a patient experiences and, consequently, the level of decisional support he or she desires from caregivers. Third, the data were collected by self-report, which may have resulted in memory biases inherent in retrospective recall.

\section{Future Directions}

The current article suggests multiple directions that may be fruitful for future studies to pursue. It would be informative to compare patient and caregiver perceptions of their decision- making styles as well as strategies for helping health care providers ascertain the manner in which important treatment decisions are being made. Patient outcomes are likely to be improved if caregivers and health care providers have a better understanding of whether patients desire autonomy or interdependence in their decision-making style. For example, if a patient has a strong preference for interdependence, health care providers can make efforts to ensure caregiver members are present when treatment options, such as RCTs, are discussed. Another avenue to explore is advancing current methodologies for understanding medical decision making by developing scales for measuring self-assessments of decision quality and preferences for autonomy as related to health care providers and caregivers. Such advances could lead to the development of highly customizable interventions to improve communication interventions for the refinement of medical decision making in clinical contexts.

Acknowledgments - The authors thank Aaron Wendel, Alexis Alberts, Hannah Rechel, Madeline Olhoeft, and Serena Smalley for their assistance with coding. They also thank Julianne Wojno for her contributions to the research team and an earlier version of this article.

Declaration of Conflicting Interests - The authors declared no potential conflicts of interest with respect to the research, authorship, and/or publication of this article.

Funding - The authors disclosed receipt of the following financial support for the research, authorship, and/or publication of this article: This work was supported by a grant from the National Cancer Institute (U54CA153604 UKY, PI: Dignan).

\section{References}

Ackerson, L. K., \& Viswanath, K. (2009). The social context of interpersonal communication and health. Journal of Health Communication, 14(Suppl. 1), 5-17. doi:10.1080/10810730902806836

Arora, N. K., Finney Rutten, L. J., Gustafson, D. H., Moser, R., \& Hawkins, R. P. (2007). Perceived helpfulness and impact of social support provided by family, friends, and health care providers to women newly diagnosed with breast cancer. Psycho-Oncology, 16, 474-486. doi:10.1002/pon.1084
Avis, N. E., Smith, K. W., Link, C. L., Hortobagyi, G. N., \& Rivera, E. (2006). Factors associated with participation in breast cancer treatment clinical trials. Journal of Clinical Oncology, 24, 18601867. doi:10.1200/JCO.2005.03.8976

Baquet, C. R., Commiskey, P., Daniel Mullins, C., \& Mishra, S. I. (2006). Recruitment and participation in clinical trials: Socio-demographic, rural/urban, and health care access predictors. Cancer Detection and Prevention, 30, 24-33. doi:10.1016/j. cdp.2005.12.001

Bogner, M. S., \& Klein, G. (1997). Naturalistic decision making in health care. In G. Klein \& C. E. Zsambok (Eds.), Naturalistic decision making (pp. 61-69). Mahwah, NJ: Lawrence Erlbaum.

Brown, R., Butow, P., Ellis, P., Boyle, F., \& Tattersall, M. H. (2004). Seeking informed consent to cancer clinical trials: Describing current practice. Social Science \& Medicine, 58, 2445-2457. doi:10.1016/j.socscimed.2003.09.007

Cader, R., Campbell, S., \& Watson, D. (2005). Cognitive continuum theory in nursing decision-making. Journal of Advanced Nursing, 49, 397-405. doi:10.1111/j.1365-2648.2004.03303.x

Caughlin, J. P. (2010). A multiple goals theory of personal relationships: Conceptual integration and program overview. Journal of Social and Personal Relationships, 27, 824-848. doi:10.1177/0265407510373262

Cegala, D. J., \& Post, D. M. (2009). The impact of patients' participation on physicians' patient-centered communication. $\mathrm{Pa}$ tient Education and Counseling, 77, 202-208. doi:10.1016/j. pec.2009.03.025

Charles, C., Gafni, A., \& Whelan, T. (1997). Shared decision-making in the medical encounter: What does it mean? (or it takes at least two to tango). Social Science \& Medicine, 44, 681-692.

Chouliara, Z., Kearney, N., Stott, D., Molassiotis, A., \& Miller, M. (2004). Perceptions of older people with cancer of information, decision making and treatment: A systematic review of selected literature. Annals of Oncology, 15, 1596-1602. doi:10.1093/ annonc/mdh423

Entwistle, V. A., Carter, S. M., Cribb, A., \& McCaffery, K. (2010). Supporting patient autonomy: The importance of clinician-patient relationships. Journal of General Internal Medicine, 25, 741-745. doi:10.1007/s11606-010-1292-2

Epstein, R. M. (2013). Whole mind and shared mind in clinical decision-making. Patient Education and Counseling, 90, 200-206.

Epstein, R. M., \& Gramling, R. E. (2013). What is shared in shared decision making? Complex decisions when the evidence is unclear. Medical Care Research and Review, 70(Suppl. 1), 94S-112S. doi:10.1177/1077558712459216

Epstein, R. M., \& Street, R. L. (2011). Shared mind: Communication, decision making, and autonomy in serious illness. Annals of Family Medicine, 9, 454-461. doi:10.1370/afm.1301

Freedman, B. (1987). Equipoise and the ethics of clinical research. New England Journal of Medicine, 317, 141-145. doi:10.1056/ NEJM198707163170304

Friedrich, M. J. (2002). Program aims to reduce cancer burden in Appalachia. Journal of the National Cancer Institute, 94, 1189-1191. doi:10.1093/jnci/94.16.1189 
Goldsmith, D. J. (2004). Communicating social support. Cambridge, UK: Cambridge University Press.

Goldsmith, D. J., \& Albrecht, T. L. (2011). Social support, social networks, and health. In T. L. Thompson, R. L. Parrott, \& J. F. Nussbaum (Eds.), Handbook of Health Communication (2nd ed., pp. 335-348). New York, NY: Routledge.

Goldsmith, D. J., \& Miller, G. A. (2014). Conceptualizing how couples talk about cancer. Health Communication, 29, 51- 63. doi:10.108 0/10410236.2012.717215

Goldsmith, D. J., Miller L. E., \& Caughlin, J. P. (2008). Openness and avoidance in couples communicating about cancer. In C. Beck (Ed.), Communication Yearbook 31 (pp. 62-115). Malden, MA: Blackwell.

Hauke, D., Reiter-Theil, S., Hoster, E., Hiddemann, W., \& Winkler, E. C. (2011). The role of relatives in decisions concerning life-prolonging treatment in patients with end-stage malignant disorders: Informants, advocates or surrogate decision-makers? Annals of Oncology, 22, 2667-2674.

Heaney, C. A., \& Israel, B. A. (2008). Social networks and social support. Health behavior and health education: Theory, research, and practice, 4, 189-210.

Hilton, B. A. (1994). The 1993 Schering lecture: Family decision- making processes about early stage breast cancer treatment. Canadian Oncology Nursing Journal, 4, 9-16.

House, J. S., \& Kahn, R. L. (1985). Measures and concepts of social support. In S. Cohen \& S. L. Syme (Eds.), Social support and health (pp. 83-108). New York: Academic Press.

Huang, B., Wyatt, S., Tucker, T., Bottorff, D., \& Lengerich, E. (2002). Cancer death rates-Appalachia, 1994-1998. Morbidity and Mortality Weekly Report, 51, 527-529.

Janssen, C., \& Pfaff, H. (2005). Psycho-social environments. In: J. Kerr, R. Weitkunat, \& M. Morett (Eds.), $A B C$ of behavior change: a guide to successful disease prevention and health promotion (pp. 153-165). London: Elsevier.

Kapp, M. B. (1991). Health care decision making by the elderly: I get by with a little help from my family. The Gerontologist, 31, 619623. doi:10.1093/geront/31.5.619

Krieger, J. L. (2014a). Family communication about cancer treatment decision-making: A description of the DECIDE typology. In E. Cohen (Ed.), Communication yearbook (Vol. 38, pp. 279-305). New York: Routledge.

Krieger, J. L. (2014b). Last resort or roll of the die? Exploring the role of metaphors in cancer clinical trials education among medically underserved populations. Journal of Health Communication, 19, 1161-1177.

Krieger, J. L., Palmer-Wackerly, A., Dailey, P., Krok, J., Schoenberg, N., \& Paskett, E. (2015). Comprehension of randomization and uncertainty in cancer clinical trials decision making among rural, Appalachian patients. Journal of Cancer Education, 30, 743748. doi:10.1007/s13187-015-0789-0

Krieger, J. L., Palmer-Wackerly, A., Krok-Schoen, J., Dailey, P., Wojno, J., Schoenberg, N., . . Dignan, M. (2015). Caregiver perceptions of their influence on cancer treatment decision making: Intersections of language, identity, and illness. Journal of Language and Social Psychology, 34, 640-656. doi:10.1177/0261927X15587556
Krieger, J. L., Parrott, R. L., \& Nussbaum, J. F. (2011). Metaphor use and health literacy: A pilot study of strategies to explain randomization in cancer clinical trials. Journal of Health Communication, 16, 3-16.

Lapinski, M. K., \& Rimal, R. N. (2005). An explication of social norms. Communication Theory, 15, 127-147. doi:10.1111/j.1468-2885.2005.tb00329.x

Loh, W. Y., Butow, P. N., Brown, R. F., \& Boyle, F. (2002). Ethical communication in clinical trials. Cancer, 95, 2414-2421.

Manne, S., \& Glassman, M. (2000). Perceived control, coping efficacy, and avoidance coping as mediators between spouses' unsupportive behaviors and cancer patients' psychological distress. Health Psychology, 19(2), 155-164. doi:10.1037/0278-6133.19.2.155

McNutt, R. A. (1989). Measuring patient preferences for health outcomes: A decision analytic approach. Patient Education and Counseling, 13, 271-279.

McNutt, R. A. (2004). Shared medical decision making: Problems, process, progress. The Journal of the American Medical Association, 292, 2516-2518. doi:10.1001/ jama.292.20.2516

Mills, E. J., Seely, D., Rachlis, B., Griffith, L., Wu, P., Wilson, K., . . . Wright, J. R. (2006). Barriers to participation in clinical trials of cancer: A meta-analysis and systematic review of patient-reported factors. The Lancet Oncology, 7, 141-148. doi:10.1016/ S1470-2045(06)70576-9

O’Hair, D., Villagran, M. M., Wittenberg, E., Brown, K., Ferguson, M., Hall, H. T., \& Doty, T. (2003). Cancer survivorship and agency model: Implications for patient choice, decision making, and influence. Health Communication, 15, 193-202. doi:10.1207/ S15327027HC1502_7

Patton, M. Q. (2002). Qualitative research and evaluation methods. Thousand Oaks, Calif: Sage Publications.

Pecchioni, L. L., \& Nussbaum, J. F. (2000). The influence of autonomy and paternalism on communicative behaviors in mother-daughter relationships prior to dependency. Health Communication, 12, 317-338. doi:10.1207/S15327027HC1204_1

Roloff, M., \& Van Swol, L. M. (2007). Shared cognition and communication within group decision making and negotiation. In D. R. Roskos-Ewoldsen \& L. Monahan (Eds.), Communication and social cognition: Theories and methods (pp. 171-195). Mahwah, NJ: Erlbaum.

Ross, S., Grant, A., Counsell, C., Gillespie, W., Russell, I., \& Prescott, R. (1999). Barriers to participation in randomised controlled trials: A systematic review. Journal of Clinical Epidemiology, 52, 11431156. doi:10.1016/ S0895-4356(99)00141-9

Schumacher, K. L., Stewart, B. J., Archbold, P. G., Caparro, M., Mutale, F., \& Agrawal, S. (2008). Effects of caregiving demand, mutuality, and preparedness on family caregiver outcomes during cancer treatment. Oncology Nursing Forum, 35, 49-56. doi:10.1188/08. ONF.49-56

Sedig, L. (2016). What's the role of autonomy in patient- and familycentered care when patients and family members don't agree? AMA Journal of Ethics, 18, 12-17.

Speice, J., Harkness, J., Laneri, H., Frankel, R., Roter, D., Kornblith, A. B., ... Holland, J. C. (2000). Involving family members in cancer care: Focus group considerations of patients and oncological providers. Psycho-Oncology, 9, 101-112. 
Street, R. L., \& Voigt, B. (1997). Patient participation in deciding breast cancer treatment and subsequent quality of life. Medical Decision Making, 17, 298-306. doi:10.1177/0272 989X9701700306

Uchino, B. N. (2009). Understanding the links between social support and physical health: A life-span perspective with emphasis on the separability of perceived and received support. Perspectives on Psychological Science, 4(3), 236- 255. doi:10.1111/j.1745-6924.2009.01122.x

Virani, S., Burke, L., Remick, S. C., \& Abraham, J. (2011). Barriers to recruitment of rural patients in cancer clinical trials. Journal of Oncology Practice, 7, 172-177. doi:10.1200/JOP.2010.000158

Zhang, A. Y., \& Siminoff, L. A. (2003). The role of the family in treatment decision making by patients with cancer. Oncology Nursing Forum, 30, 1022-1028. doi:10.1188/03. ONF.1022-1028

\section{Author Biographies}

Janice L. Krieger, PhD, is the Director of the STEM Translational Communication Center and associate professor of Advertising in the University of Florida College of Journalism and Communications in Gainesville, Florida, USA.
Jessica L. Krok-Schoen, $\mathrm{PhD}$, is a postdoctoral research fellow at The Ohio Sate University Comprehensive Cancer Center, Columbus, Ohio, USA.

Phokeng M. Dailey, MA, is a doctoral student at The Ohio State University School of Communication in Columbus, Ohio, USA.

Angela L. Palmer-Wackerly, $\mathrm{PhD}$, is an assistant professor in Communication Studies at the University of Nebraska-Lincoln, Lincoln, NE.

Nancy Schoenberg, $\mathrm{PhD}$, is the Marion Pearsall Professor of Behavioral Science at the University of Kentucky, College of Medicine.

Electra D. Paskett, PhD, is the Marion N. Rowley Professor of oncology and director of the Division of Cancer Prevention and Control, Department of Internal Medicine, College of Medicine, and associate director of Population Sciences in the Comprehensive Cancer Center at the Ohio State University.

Mark Dignan, $\mathrm{PhD}$, is a professor in the Department of Internal Medicine and director of the Prevention Research Center in the College of Medicine at the University of Kentucky. 